\title{
Critical WBGT for 4 protective clothing made of fabrics with different Total Heat Loss values
}

\author{
Aitor Coca ${ }^{1 *}$, Jung-Hyun Kim¹, Candi Ashley², Thomas Bernard ${ }^{2}$ \\ From 15th International Conference on Environmental Ergonomics (ICEE XV) \\ Portsmouth, UK. 28 June - 3 July 2015
}

\begin{abstract}
Introduction
Managing heat stress in the workplace while wearing protective clothing $(\mathrm{PC})$ is critical for worker safety and health. There is a variety of $\mathrm{PC}$, such as fire-fighting ensembles, emergency medical clothing, CBRN suits, etc., designed to protect the wearer's body from specific hazards, which have different levels of protection and thus different clothing thermal characteristics (thermal and vapour resistances). This study evaluated the critical wet bulb globe temperature (WBGT $\mathrm{Writ}_{\text {) }}$ ) of PC ensembles with four different total heat loss values determined by a sweating hotplate (SHP) test.
\end{abstract}

\section{Methods}

Seven healthy male adults participated in this study. Subjects were acclimatized for 5 days prior to the tests of five $\mathrm{PC}$ ensembles in random order. The five tests consisted of four PC ensembles with identical design but with different Total Heat Loss (THL) values, and control working clothes. Control is the cotton regular working clothes; PC-A was a prototype with a THL value of $904 \mathrm{~W} / \mathrm{m}^{2}$; PC-B had a THL value of $700 \mathrm{~W} \cdot \mathrm{m}^{-2}$; PC-C was another prototype with a THL value of $500 \mathrm{~W} . \mathrm{m}^{-2}$; and PC-D was a commercially available chemical PE with a THL value of $191 \mathrm{~W} . \mathrm{m}^{-2}$. Subjects walked on a treadmill at a metabolic work rate of $160 \mathrm{~W} \cdot \mathrm{m}^{-2}$ in a climatic chamber that slowly increased the level of heat stress when their core temperature reached a steady-state. WBGT was set at $25.5(50 \% \mathrm{rh})$ at the start of the session and the ambient temperature was increased 1 degree every 5 minutes after steady-state. The point at which the core temperature began to increase was defined as the inflection point, and the WBGT recorded 5 min before

\footnotetext{
* Correspondence: esq6@cdc.gov

${ }^{1}$ NIOSH/NPPTL, Pittsburgh, PA, USA

Full list of author information is available at the end of the article
}

the inflection point was determined as the $\mathrm{WBGT}_{\text {crit }}$ for each PE.

\section{Results}

Figure 1 shows the comparison of the different THL values with the $\mathrm{WBGT}_{\text {crit }}$. For control working clothes, $\mathrm{WBGT}_{\text {crit }}$ is significantly different from any of the PC tested. The PC built with the lowest THL value also has a significantly lower $\mathrm{WBGT}_{\text {crit }}$ than the other PC tested. However, there are no significant differences in WBGT $_{\text {crit }}$ between PC built from fabrics that are above $500 \mathrm{~W} / \mathrm{m}^{2}$.

The materials used to manufacture these PC were rated in a range from a very low (PC-D, $191 \mathrm{~W} . \mathrm{m}^{-2}$ ) and a very high THL value (PC-A, 904 W.m ${ }^{-2}$ ). Three of the PC did not show any differences on $\mathrm{WBGT}_{\text {crit }}$, even with THL differences of about $400 \mathrm{~W} \cdot \mathrm{m}^{-2}$.

\section{Conclusion}

In summary, the results of this research supports that the SHP-THL value may be effective in distinguishing basic thermal characteristics of the fabrics used for PC;

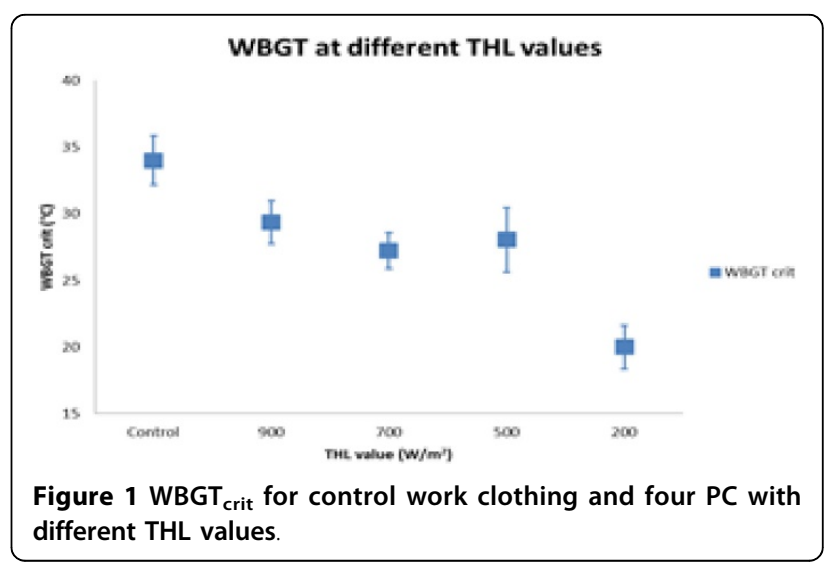


however, the overall effect of fabric THL ratings on PC $\mathrm{WBGT}_{\text {crit }}$ was not linearly related in our study. Moreover, this preliminary data suggest that heat stress caused by PC with different THL values, between 500 and $900 \mathrm{~W} . \mathrm{m}^{-2}$, may not be physiologically different in terms of $\mathrm{WBGT}_{\text {crit }}$.

\section{Disclaimer}

The findings and conclusions of this abstract are those of the authors and do not necessarily reflect the views of the National Institute for Occupational Safety and Health.

\section{Authors' details}

${ }^{1} \mathrm{NIOSH} / \mathrm{NPPTL}$, Pittsburgh, PA, USA. ${ }^{2}$ University of South Florida, Tampa, FL, USA.

Published: 14 September 2015

- Convenient online submission

- Thorough peer review

- No space constraints or color figure charges

- Immediate publication on acceptance

- Inclusion in PubMed, CAS, Scopus and Google Scholar

- Research which is freely available for redistribution 